The Aproximate Average Quantities of the Products that can be Obtained FROM TFN POUNDS OF CITRIC ACID.

Obtained, grams.

Citric acid.............................. 4530

Acetone dicarbonic acid. ..................... 3300

Di-isonitroso acetone. ......................... 1089

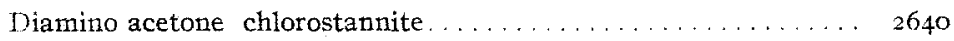

Jiaminoacetone hydrochloride.................. I 200

2-Thiol-4-aminomethylglyoxaline hydrochloride (pure) ........ 950

4-Flydroxymethylglyoxaline picrate...................

(I) From the above $950 \mathrm{~g} .2$-thiol compound ......... 1670

(2) From the solid (C) (see experimental part)......... 185

4-Hydroxymethylglyoxaline hydrochloride............ 740

4-Chloromethylglyoxaline hydrochloride.............. 700

4-Cyanomethylglyoxaline..................... 200

Imidazolylethylamine dihydrochloride $\ldots \ldots \ldots \ldots \ldots \ldots \ldots \ldots \ldots$

CatCAgO, ILi,yors.

[Contribution from The, Otho S. A. Sprague Memorial Institute and the DEPartment of Pathology of The. University of Chicago.]

\title{
THE ELECTRONIC CONSTITUTIONS OF ACETOACETIC AND CITRIC ACIDS AND SOME OF THEIR DERIVATIVES.
}

By Mition Th, Hanke and KarL K. Koessler.

Received August 12, 1918.

The first step in the synthesis of imidazolyl ethyl amine ${ }^{1}$ is the preparation of acetone dicarbonic acid by treatment of citric acid with fuming sulfuric acid.

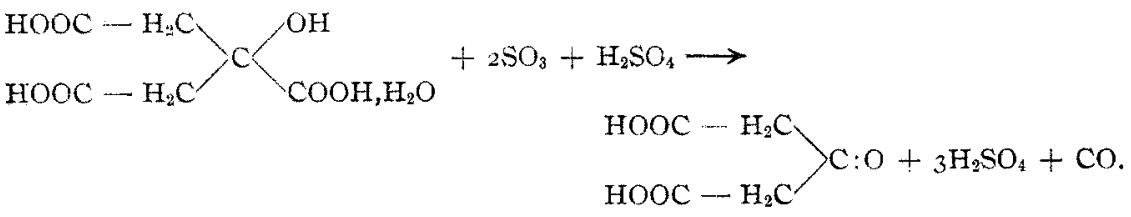

It will be noticed from the above equation that it is the central carboxyl group that is removed as carbon monoxide. This selective action toward the central carboxyl group is hard to explain unless the electrical constitution of citric acid is considered. The following formula shows how much of the electrical constitution of citric acid can be directly foretold by inspection and by a knowledge of its simplest reactions. ${ }^{2}$

It will be noted that the unknown electrical charges are limited entirely to the linkages between the carbon atoms. In attempting to solve the problem of the direction of electrical field in these bonds, the easiest point of attack is the union between the carboxyl groups and the carbon atoms to which they are attached.

1 See preceding article.

2 The heavy dashes represent electrical fields of undetermined polarity. 


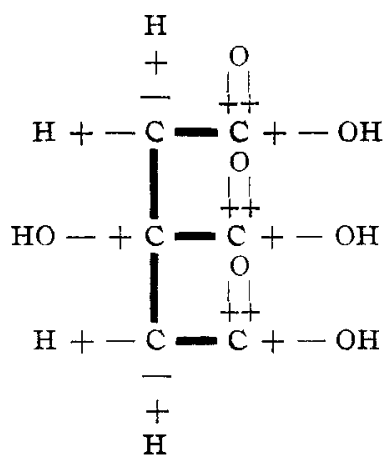

When citric acid is treated with fuming sulfuric acid at $60-70^{\circ}$, all water being excluded (see preceding article), the central carboxyl group escapes as carbon monoxide. The two end carboxyl groups are unaffected. There is no charring of the citric acid nor of the product formed from it, acetone dicarbonic acid. Sulfur dioxide is not formed if the mixture is not superheated. The reason for this selection of the central carboxyl group must be due to a difference in the direction of the valence force holding this group from that holding the two end carboxyl groups. ${ }^{1}$

Carbon monoxide must have one or both of the following electrical structures:

$$
\mathrm{C}_{+}^{+} \mathrm{O}(\mathrm{I}) \text { or }{ }_{-}^{+} \mathrm{C}_{+}^{+} \mathrm{O} \mathrm{O}(2) \text {. }
$$

Formula I represents the inactive form of carbon monoxide, inactive because of the entire absence of free valences. Formula 2 represents the active variety of carbon monoxide, which, because of the presence of free valences, can unite with other substances. Although most of the carbon monoxide may be in the inactive form, some of it is certainly in the active form, which is proven by the addition reactions of this substance. When carbon monoxide unites with other substances, it always absorbs one positive and one negative group. ${ }^{2}$ The absorption of potassium hydroxide to give potassium formate is a good example of this kind of absorption. This fact proves that the electrical structure of active carbon monoxide must be Formula 2.

The central carboxyl group in citric acid must therefore have the electrical constitution

$$
\stackrel{++}{\mathrm{C}}+-\mathrm{OH}
$$

If the end carboxyl groups differ from the central one, they must differ in electrical charges and there is but one possible difference; they must have charges as follows:

${ }^{1}$ Harry Shipley Fry, Thıs Journal, 34, 664 (I9I3); 36, 256 (IgI5).

${ }^{2}$ This is true for certain, of course, only when the substance absorbed is neither an oxidizing nor a reducing substance. 


$$
\begin{gathered}
\mathrm{O} \\
++ \\
+\mathrm{C}+-\mathrm{OH}
\end{gathered}
$$

The known electrical constitution of citric acid would then enlarge to

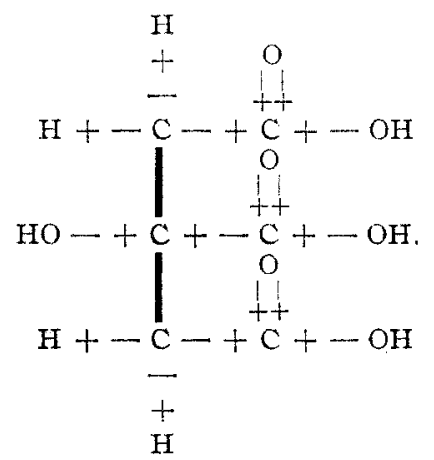

That this is actually the correct formula is proven by a study of acetone dicarbonic acid, which is obtained from citric acid by treatmemt with fuming sulfuric acid. Its structural formula is<smiles>O=C(O)CCCC(=O)O</smiles>

When this acid is boiled in water solution, warmed in mineral acid or caustic alkali solution, or melted, it breaks up into two molecules of carbon dioxide and one of acetone. The same decomposition also occurs when its salts are kept at room temperature.

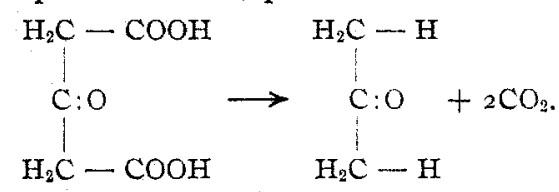

The two carboxyl groups are eliminated as carbon dioxide, not monoxide, which proves that their carbon atoms must have held 4 positive electrical charges since carbon dioxide must have the formula

$$
\mathrm{O}=+\mathrm{C}+=\mathrm{O} \text {. }
$$

In the above formula for citric acid, there still remain two bonds whose polarity has not been determined. That the problem of solving these valences is identical with that of solving the electrical structure of acetone can be readily seen from the following schematic formulas:<smiles>O=C(O)CCC(CC(=O)O)CC(=O)CC(CC(=O)O)CC(=O)O</smiles> 
The nucleus of the citric acid molecule is really acetone.

From an inspection of the formula and chemical behavior of acetone, one would be strongly inclined to believe that it was a perfectly symmetrical molecule having the following electrical structure:

$$
\begin{gathered}
\mathrm{H} \\
\mathrm{t} \\
\mathrm{H}+-\frac{\mathrm{C}}{-}+\mathrm{H} \\
+ \\
\mathrm{C}+=0 \\
\frac{+}{\mathrm{C}}-+\mathrm{H} \\
\mathrm{H}+\frac{+}{+}
\end{gathered}
$$

That this is actually the case can be proven by a consideration of the chemistry of acetoacetic acid, acetic acid and keten.

As is well known, acetoacetic acid undergoes two kinds of hydrolysis the one giving rise to acetone and carbon dioxide, the other to two molecules of acetic acid. An inspection of the formula and chemical reactions of acetoacetic acid gives the following electrical formula:

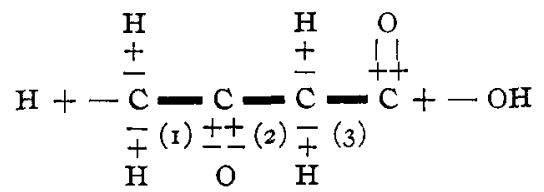

Since carbon dioxide is evolved by hydrolysis and heat, the carboxyl group must contain quadruply positive carbon. Linkage (3) must therefore have the electrical constitution $(-+)$.

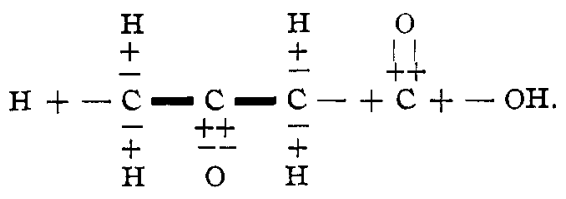

Since by another type of hydrolysis linkage (2) is ruptured so that two molecules of acetic acid are formed, the hydrogen atom going to the $\alpha$-carbon atom in the acetoacetic acid, this linkage must have the electrical constitution $(+\rightarrow)$.<smiles>[CH][C+]([C+]C(C)=O)OCC</smiles> 
The acetone formed by the hydrolysis of acetoacetic acid must therefore have the following partial electronic structure:

$$
\mathrm{H}_{3} \mathrm{C}-\underset{++}{\mathrm{C}}+\frac{\frac{\mathrm{H}}{\mathrm{t}}}{\mathrm{C}}-\underset{+}{\mathrm{H}}+\mathrm{H}
$$

Linkage ( $\mathrm{I}$ ) is apparently still unsolved, but going back to acetoacetic acid, Formula A above, it is clear that the left-hand end of the acetone molecule is electronically acetic acid, because acetoacetic acid gives acetic acid by hydrolysis. If the electronic formula for acetic acid were known, the entire formula for acetone would be self-evident.

By observing the right-hand end of the acetoacetic acid, Formula A above, which by hydrolysis gives acetic acid, the electronic formula for acetic acid would appear to be ${ }^{1}$

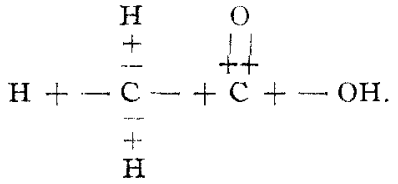

That this is actually the case can be proven by a consideration of the properties of keten. ${ }^{2}$ Keten has the structural formula $\mathrm{CH}_{2}=\mathrm{C}=\mathrm{O}$. It might have any one of the three possible electronic formulas

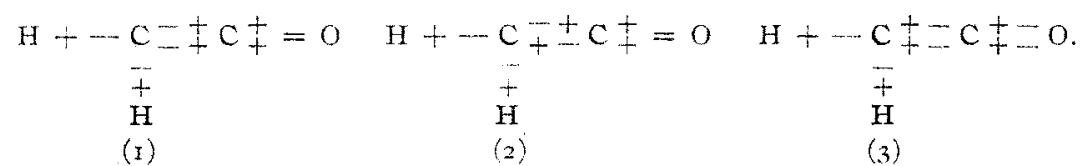

The direction in which water and other substances of undoubted electronic structure are absorbed ought to decide which of these 3 possible formulas is correct. Keten absorbs water readily. If Formula I were correct, acetic acid should be the only product.

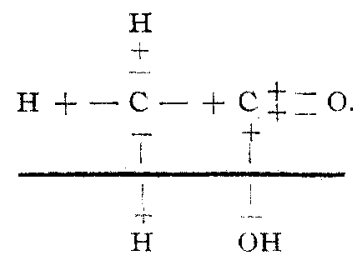

1 See also articles by Harry Shipley Fry, Loc. cit.

"Wilsmore, Proc. Chem. Soc, 23, 229 (1907); J. Chem. Soc. (London), 91, 1030-4I (1907); H. Standinger and H. W. Klever, Ber., 4I, 594-600 (I 908); F. Chick and N. T. M. Wilsmore, Proc. Shem. Soc., 24, 77-78 (1908). 
If Formula 2 were correct, a mixture of acetic acid and glycollic aldehyde should be obtained. If Formula 3 were correct, only glycollic aldehyde should be obtained. As a matter of fact, ${ }^{1}$ not a trace of glycollic aldehyde is formed, the only product being acetic acid. As further evidence of the correctness of these conclusions, the following might be convincing: With alcohols, keten gives esters of acetic acid; with amines, acetamides are formed. Phenylhydrazine gives the phenylhydrazide of acetic acid; hydrogen chloride gives acetyl chloride and hydrogen sulfide gives the anhydride of thioacetic acid. These entirely one-sided reactions can be explained only on the assumption that the electronic Formula I for keten is correct. It follows then as a natural corollary, that acetic acid must have the very symmetrical electronic formula<smiles>[CH][CH+]=O</smiles>

and that the two ends of the acetone molecule are perfectly symmetrical, giving to that substance the electronic formula

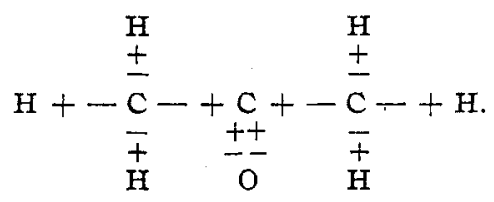

The complete formula for acetoacetic acid must then be

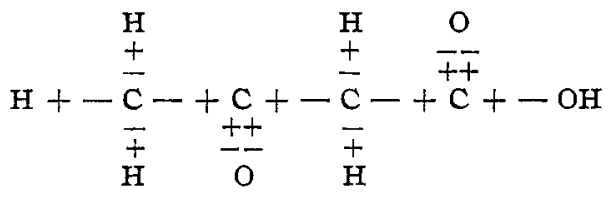

that of acetone dicarbonic acid

and that of citric ac.

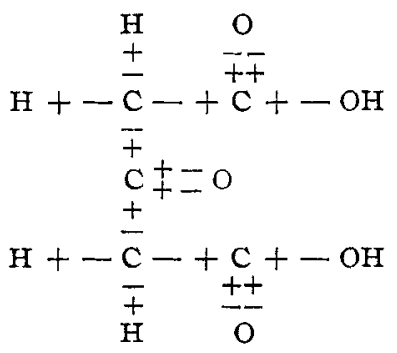

1 Loc. cit. 
Chicago, illinois.

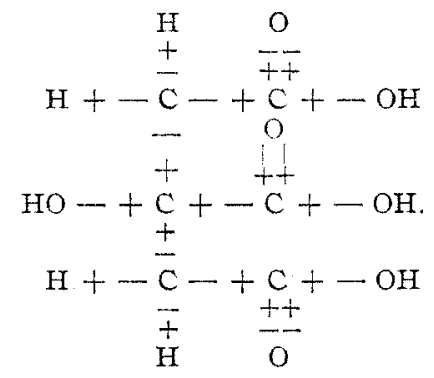

[CONTRIBUTION FROM THE CHEMICAL LABORATORY OF THE UNIVERSITY OF ILLINOIS.] THE REACTION BETWEEN ACID HALIDES AND ALDEHYDES. I.

BY ROgER ADAMS AND E. H, VOLLWEILER.

Received August $17,1918$.

Although the addition and condensation reactions of aldehydes and ketones have been widely investigated, it is a surprising fact that their action with acid halides has received comparatively little attention. In only one or two of the largest and most extensive text-books on organic chemistry is this reaction even mentioned. An investigation was therefore started in this laboratory to ascertain whether or not the reaction between aldehydes and acid halides is a general one in the aliphatic as well as aromatic series, and to determine the structure, properties and reactions of the resulting compounds. From the results so far attained, the indications are that the reaction is indeed a general one.

In this paper are given (I) a description of a number of the addition compounds prepared by the action of benzaldehyde and certain substituted benzaldehydes on various aromatic acid chlorides and bromides; (2) a description of a series of addition compounds of oxalyl bromide and aromatic aldehydes; (3) the proof of the structure of these compounds as shown by a study of the substance produced from benzaldehyde and benzoyl bromide; (4) a description of the preliminary study of the reactions of these compounds with various reagents.

A brief review of what already has appeared in the literature concerning these compounds is as follows: Wurtz ${ }^{1}$ obtained a compound by the action of chlorine on acetaldehyde which Simpson ${ }^{2}$ and Franchimont ${ }^{3}$ proved to be the same as that obtained by the action of acetyl chloride on acetaldehyde, and which Schiff ${ }^{4}$ later showed to have the structure of the addition compound $\mathrm{CH}_{3} \mathrm{CHClOCOCH}$. A number of similar addition compounds of acetaldehyde with three other aliphatic acid halides

1 Ann., 102, 94 (1857).

2Ibid., 109, 156 (1859).

3 Recucil, 1, 243 (1882).

- Ber., 9, 304 (1876). 